\title{
Advances and prospects in the study of certain diseases due to infections by Subgroub A Chlamydia
}

\author{
BARRIE R. JONES \\ From Moorfields Eye Hospital and the Institute of Ophthalmology, University of London
}

The work of our group in studying chlamydial infections of the genital tract and eye was presented to The Medical Society for the Study of Venereal Diseases in 1964 and to the Ophthalmological Society of the United Kingdom in 1956, 1961, and 1966 (Jones, Andrews, Henderson, and Schofield, 1957; Collier, Duke-Elder, and Jones, 1958, 1960; Jones, Collier, and Smith, 1959; Jones, 1960, 1961, 1964a,b; Jones and Collier, 1962; Jones, Al-Hussaini, and Dunlop, 1964, 1965; Al-Hussaini, Jones, and Dunlop, 1964, 1965; Dunlop, Jones, and Al-Hussaini, 1964, 1965a; Dunlop, Al-Hussaini, Garland, Treharne, Harper, and Jones, 1965b; Dunlop, Harper, AlHussaini, Garland, Treharne, Wright, and Jones, 1966a; Dunlop, Al-Hussaini, Freedman, Garland, Harper, Jones, Race, duToit, Treharne, and Wright, 1966b; Freedman, Al-Hussaini, Dunlop, Emarah, Garland, Harper, Jones, Race, duToit, Treharne, and Wright, 1966; Jones, Al-Hussaini, Dunlop, Emarah, Freedman, Garland, Harper, Race, duToit, and Treharne, 1966; Harper, 1966; Harper, AlHussaini, Dunlop, Emarah, Freedman, Garland, Jones, Race, duToit, Treharne, and Wright, 1966; Harper, Dwyer, Garland, Jones, Treharne, Dunlop, Freedman, and Race, 1967; Dunlop, Freedman, Garland, Harper, Jones, Race, duToit, and Treharne, 1967).

In these studies it was shown that new cases of trachoma were presenting in London along with inclusion conjunctivitis and the intermediate syndrome that we defined, namely TRIC Agent Punctate Keratitis (TPK), (Jones, 1964a; Jones and others, 1966). The clinical features of these three syndromes merged one into another. In certain patients one syndrome in one eye was seen to co-exist with another syndrome in the other eye: thus the clinical picture of inclusion conjunctivitis was seen in one eye with trachoma in the other; or inclusion conjunctivitis in one eye with TPK in the other; or TPK in one eye with trachoma in the other. In several patients the clinical picture of inclusion conjunctivitis or of TPK was seen to change in time into that of trachoma; in

Read at a meeting of the MSSVD in November, 1970 other patients the clinical picture of inclusion conjunctivitis was seen to change into that of TPK.

For these reasons, it did not seem desirable to label the chlamydial isolates obtained from these patients too rigidly as either trachoma agent or inclusion conjunctivitis agent (Jones and others, 1959); so, pending the possible development of laboratory methods for typing these isolates, the expedient of referring to them all as TRIC agent came into general use (Gear, Gordon, Jones, and Bell, 1963).

The apparently continuous spectrum, or overlapping spectra, of clinical appearances, with transitions from one form to another, led to the postulation that the genital mode of transmission accepted for the agent of inclusion conjunctivitis might also apply to the cases of trachoma appearing in London.

By means of inclusion-finding by staining clinical specimens with iodine, Giemsa's stain, or fluorescent antibody (FA), and isolation in the yolk sac of chick embryos, coupled with detailed examination of the eye and the genital tract of the patients studied, we were able to establish the following points:

(1) Nearly all patients presenting with active TRIC infection of the eye in London, including those with trachoma, had genital inflammation; in the great majority of cases this took the form of 'non-specific' urethritis (NSU) in the males and 'non-specific' cervicitis in the females. Many of these persons had trichomoniasis, and some had other associated genital infection (Dunlop and other, 1967).

(2) In the genital tract of at least 14 per cent. and up to 29 per cent. of the mothers, and at least 21 per cent. and up to 42 per cent. of the fathers of babies with TRIC ophthalmia neonatorum (ON), we were able to demonstrate the presence of chlamydial agents. Presumably, all of these mothers and most of the fathers had TRIC infection of the genital tract at the time of delivery. Hence it was clear that our tests for these agents were frustratingly insensitive (Dunlop and others, 1967). 
(3) In at least 15 per cent. and up to 36 per cent. of patients presenting with TRIC infection of the eye in London, we were able to demonstrate the presence of chlamydial agents in the genital tract (Dunlop and others, 1967).

(4) In at least 9 per cent. and up to 25 per cent. of men presenting with NSU, we demonstrated the presence of Chlamydia in urethral material: in view of the findings in fathers of babies with TRIC ON, this suggested that a great deal of the NSU in London was due to Chlamydia, and that this reservoir of genital infection was the source of sexually transmitted infection of the eye (Dunlop and others, 1965a, 1967).

Chlamydial agents are divided according to whether or not their inclusion bodies contain iodinestaining material, into:

SUBGROUP A: Iodine-positive inclusion bodies TRIC agents

Most LGV agents

SUBGROUP B: Iodine-negative inclusion bodies Some agents isolated from LGV

Psittacosis agents

Ornithosis agents

Agents of cattle or sheep abortion and other animal disease of the respiratory, genital, or articular systems

During 1966 we isolated a Subgroup B Chlamydia in eggs that had been inoculated with synovial fluid from the knee joint of a patient suffering from Reiter's disease (Dunlop and others, 1966b, 1967; Harper and others, 1966). Following this we recognized the problem of cross-infection in our laboratory, apparently mediated by aerosols during the harvesting of infected egg (Harper and others, 1967). There is therefore some uncertainty concerning the origin of this Subgroup B isolate.

Three points then became clear:

(1) No laboratory had suggested the need for, or reported the results of, concomitant control cultures of coded, dummy non-infected specimens to detect the presence of cross-infection during diagnostic or other cultivation of chlamydial agents. Since that time, all our cultural work has included strict precautions to prevent cross-infection and specimens have included at least 10 per cent. of such coded controls: every one of over 400 control passages has remained free from cross-infection.

(2) Our earlier figures of the prevalence of chlamydial infection were probably slightly enlarged by some false positives obtained by culture in yolk sac.
(3) It was clear that even very large-scale studies using the then available, frustratingly insensitive methods for detecting chlamydial agents, could not provide completely convincing data on the proportion of NSU, or other genital disease, which was actually due to chlamydial infection.

The prime objective was therefore the development of more sensitive methods for detecting Chlamydia. Gordon, Dressler, and Quan (1967) had used a cellculture method of cultivating egg-grown TRIC agents. Dr. Francis Gordon and Mrs. Alice Quan came to work in our laboratory to assess the feasibility of adapting this to diagnostic requirements, and to test this technique on clinical specimens in parallel with isolation in yolk sac. This study demonstrated that centrifugation of clinical specimens onto irradiated McCoy cell monolayers yielded primary isolates of Chlamydia, and that when applied to a range of ocular and genital material obtained from patients in London, and some specimens from trachomatous patients in Iran, the method was markedly superior to isolation in eggs (Gordon, Harper, Quan, Treharne, Dwyer, and Garland, 1969; Dunlop, Hare, Darougar, Jones, and Rice, 1969).

In our laboratory, a study using the guinea-pig model of Subgroup B chlamydial infection of the eye has shown that, for the diagnosis of infection, isolation in McCoy cells is superior to isolation in yolk sac and to detection of inclusions by FA, which in turn is more sensitive than Giemsa's stain (Treharne, 1971).

The results of our further application of this method of isolation, in comparison with other methods of diagnosing chlamydial infection, confirm this superiority of cell culture (Darougar, Dwyer, Treharne, Harper, Garland, and Jones, 1971a), and more recent developments have enabled us to simplify the original technique (Darougar, Kinnison, and Jones, 1971b). We now have a rapid, practical, and highly sensitive, though still rather complicated, technique for isolating chlamydial agents that would appear to have overcome the first major obstacle that has blocked progress in the study of genital disease due to Chlamydia.

The second long-standing obstacle to the elucidation of the problems of chlamydial disease has been the lack of usable biological markers with which to identify, separate, and trace the roles of various strains in pathogenesis and in epidemiological studies. The development by Wang and Grayston (1970) of the micro-immunofluorescence (micro-IF) test for typing chlamydial isolates has provided a practicable method that constitutes the second main advance in this area of medicine. We have confirmed 
the practicability of the technique and its superiority over an earlier typing system, have evaluated the specificity of the results, and have extended the findings of Wang and Grayston (Treharne, Katzenelson, Davey, and Gray, 1971). Our results have persuaded Wang and Grayston to re-examine their material and have led to the recognition of three serotypes of Subgroup A chlamydial isolates of LGV agent (Treharne and others, 1971; Wang and Grayston, 1971).

All the TRIC agent isolates from London that have been typed in our laboratory so far, have fallen into serotypes $\mathrm{D}, \mathrm{E}$, or $\mathrm{F}$, including the isolates GB/IOL-10/OT (Type D) and GB/IOL-34/OT (Type E) that came from eyes of persons presenting the clinical picture of trachoma.

All the genital and rectal isolates from London that have been typed so far, have been Types D, E, or F. In the cases of each of the three patients from whom isolates have been secured and typed from both the eye and the genital tract, the isolates from the two different sites in each patient have both been of the same type. Patients of particular interest are Mr. S., who presented with trachoma, from whom both the ocular isolate GB/IOL-10/OT and the urethral isolate $\mathrm{GB} / \mathrm{IOL}-11 / \mathrm{GU}$ are Type $\mathrm{D}$, and $\mathrm{Mr}$. B. L., who also presented with trachoma, from whom both the ocular isolate GB/IOL-34/OT and the urethral isolate $\mathrm{GB} / \mathrm{IOL}-36 / \mathrm{GU}$ are Type $\mathrm{E}$. Similarly, Miss A.B., who presented with TRIC agent punctate kerato-conjunctivitis (TPK), gave an ocular isolate $\mathrm{GB} / \mathrm{IOL}-14 / \mathrm{OPK}$ and a cervical isolate $\mathrm{GB} / \mathrm{IOL}-15 / \mathrm{GCX}$, both of which are Type $\mathrm{F}$.

These findings support the belief that sexual transmission, with genital-to-eye transfer, is an important factor in the spread of these eye diseases in London (Dunlop and others, 1965a, 1967).

On the other hand, all the isolates originating from Oriental or African trachoma that have been serotyped in our laboratory so far, have fallen into serotypes $\mathrm{A}, \mathrm{B}$, or $\mathrm{C}$, with the exception of two that have been Type D; namely, IR/IOL-235/OT from Deylam Sofla, Khusistan, Iran, and WAG/MRC-1/ OT from Gambia, West Africa. This observation may suggest that genital-to-eye transmission from a genital reservoir may occur also in countries with a high prevalence of trachoma due to TRIC Types $\mathrm{A}, \mathrm{B}$, or $\mathrm{C}$ of presumed eye-to-eye transmission; or alternatively that Type $\mathrm{D}$ may sometimes spread by eye-to-eye transmission if favourable conditions exist for this mode of transmission (Darougar, Treharne, Dwyer, Kinnison, and Jones, 1971c).

Early in our studies it became apparent that the clinical appearances due to inclusion-positive chlamydial infections of the eye in London (Jones,
1965 ; Jones and others, 1966) extended right into the appearances which had been described as occurring with lymphogranuloma venereum (LGV) infections of the eye, giving a Parinaud's oculoglandular syndrome with gross conjunctivitis, episcleritis, and painful and visible preauricular adenitis (Curth, Curth, and Sanders, 1940). This suggested that, until it became practicable to identify LGV agents in the laboratory and readily to distinguish them from TRIC agents, there was the possibility of confusing atypical forms of one infection with the other, or conversely of falsely naming LGV isolates as TRIC isolates, especially if they came from unusual sites. This difficulty is very real with isolates obtained from the rectum (Darougar and others, 1971b; Dunlop, Hare, Darougar, and Jones, 1971). Our recent results, using the micro-IF typing test to serotype a series of new isolates from clinical cases of LGV, gave a strong indication that the micro-IF test can readily separate the Subgroup B LGV isolates from TRIC isolates, whatever site they come from (Treharne, Davey, Gray, and Jones, 1972). This test further divided $\mathrm{LGV}$ isolates into three serotypes, with our isolates LGV//GB/IOL-253/LN, from a bubo in London, falling into the LGV III group.

The results of the application of these improved laboratory methods to the study of NSU, suggest that Subgroup A chlamydial infection may account for 44 per cent. of NSU in London (Dunlop and others, 1971). That this is lower than the proportion of isolations of Chlamydia from the genital tract in the cases of persons presenting with TRIC infection of the eye ( 70 to 80 per cent.) may suggest that not all NSU in London is due to chlamydial infection. However, the studies are not yet sufficiently advanced to allow firm conclusions to be drawn.

The role is not yet clear of the Subgroup B chlamydial agents isolated from yolk sacs inoculated with material from patients with LGV (Schachter, 1967a; Treharne and others, 1972) or from patients with Reiter's disease (Schachter, 1967b). Although it is possible that some of these may be laboratory artefacts (Harper and others, 1967) it would seem likely that Subgroup B Chlamydia may be responsible for a proportion of the cases of ocular, genital, articular, or other disease, especially in patients with rather widespread disease of an invasive nature. However, the interrelation of these organisms and the Subgroup B Chlamydia isolated from birds or animals, awaits clarification by application of the micro-IF typing system in conjunction with various other biological markers and parameters of pathogenicity.

In conclusion, it would appear that, with isolation 
in irradiated McCoy cell cultures, micro-IF typing, and type-specific immunofluorescence antibody measurements, we now have the most exciting methods to apply to the study of 'non-specific' genital infection in both males and females, to Reiter's disease, to salpingitis, to abacterial cystitis, and to proctitis, and to the problems of abortion and infertility, in addition to the problems of conjunctivitis, keratitis, uveitis, and other ocular disease. The coming period should see the evaluation of the prevalence and importance of TRIC, LGV, and other chlamydial infections of the genital tract, and should pave the way to clearly defined trials of therapy of disease due to these agents.

\section{Summary}

Until recently, progress in the study of genital disease due to Chlamydia was hampered by the lack of sensitive microbiological methods of detection and identification.

(1) The development of an irradiated McCoy cell culture system, combining centrifugation of clinical specimens onto the cell monolayer, proved to be a more sensitive method of detection than the methods previously used. Subsequent modifications to the cell culture technique have made it an even more practicable and rapid diagnostic aid.

(2) The introduction of the micro-IF typing test has overcome the lack of effective biological markers to identify, separate, and trace the roles of different strains in pathogenesis and in epidemiological studies. The test has facilitated serotyping of chlamydial agents from ocular, genital and rectal infections in London, and of ocular isolates from trachoma and endemic areas, and has divided TRIC agents into six major serotypes. LGV agents can now be readily distinguished from TRIC agents and furthermore can be separated into three major LGV serotypes.

(3) Application of the micro-IF test for the measurement of type-specific antibody in the sera of patients would appear to give a much more senstive indication of chlamydial infection than the methods previously used.

\section{References}

Al-Hussaini, M. K., Jones, B. R., and Dunlop, E. M. C. (1964) Brit. F. vener. Dis., 40, 25

,,--- (1965) Rev. int. Trachome, 42, 7

Collier, L. H., DUKE-Elder, S., and Jones, B. R. (1958) Brit. F. Ophthal., 42, 705

$\longrightarrow,-\longrightarrow$ (1960) Ibid., 44, 65

Curth, W., CurTh, H. O., and SANDers, M. (1940) $\mathcal{F} \cdot$ Amer. med. Ass., 115, 445
Darougar, S., DwYer, R. St. C., Treharne, J. D.. HARPER. I. A., GarLaND, J. A., and JoNes, B. R. (1971a) In 'Trachoma and Allied Diseases, 1970', ed. R. L. Nichols. Excerpta Medica, Amsterdam and New York

-, Kinnison, J. R., and Jones, B. R. (1971b) Idem

- Treharne, J. D., Dwyer, R. St. C., Kinnison, J. R., and JoNEs, B. R. (1971c) Brit. F. Ophthal., 55, 591

Dunlop, E. M. C., Al-Hussaini, M. K., Freedman, A., GarLAND, J. A., HARPER, I. A., JoNes, B. R., RaCE, J. W., DUTOIT, M. S., TREHARNE, J. D., and WRIGHT, D. J. M. (1966b) Trans. ophthal. Soc. U.K., 86, 321

- - - Garland, J. A., Treharne, J. D., Harper, I. A., and Jones, B. R. (1965b) Lancet, 1, 1125

- Freedman, A., Garland, J. A., Harper, I. A., JONES, B. R.; RACE, J. W., DUTOIT, M. S., and TREHARNE, J. D. (1967) Amer. F. Ophthal., 63, 1073

-, HARE, M. J., Darougar, S., JoNES, B. R. (1971) In 'Trachoma and Allied Diseases, 1970', ed. R. L. Nichols. Excerpta Medica, Amsterdam and New York. I.C.S. No. 223 , p. 507

$\longrightarrow,-,-$ and RICE, N. S. C. (1969) $\mathcal{F}$. infect. Dis., 120, 463

-, Harper, I. A., Al-Hussaini, M. K., Garland, J. A., Treharne J. D., Wright, D. J. M., and Jones, B. R. (1966a) Brit. F. vener. Dis., 42, 77

- JONEs, B. R., and AL-HussainI, M. K. (1964) Ibid., 40, 33

$\longrightarrow,-,-1$ (1965a) Rev. int. Trachome, 42, 14

Freedman, A., Al-Hussaini, M. K., Dunlop, E. M. C., EMARAH, M. H. M., GARLAND, J. A., HaRPER, I. A., JoNES, B. R., RACE, J. W., DU TOIT, M. S., TREHARNE, J. D., and WRIGHT, D. J. M. (1966) Trans. ophthal. Soc. U.K., 86, 313

Gear, J. H. S., Gordon, F. B., Jones, B. R., and Bell, S. D. Jr. (1963) Nature (Lond.), 197, 26

GoRDON, F. B., DRESSLER, H. R., and QUAN, A. L. (1967) Amer. f. Ophthal., 63, 1044

-, Harper, I. A., Quan, A. L., Treharne, J. D., DWYer, R. St. C., and Garland, J. A. (1969) $\mathcal{F}$. infect. Dis., 120, 451

HARPER, I. A. (1966) Brit. F. vener. Dis., 42, 71

- Al-Hussaini, M. K., Dunlop, E. M. C., Emarah, M. H. M., Freedman, A., Garland, J. A., Jones, B. R., Race, J. W., DU Toit, M. S., Treharne, J. D., and WRIGHT, D. J. M. (1966) Trans. ophthal. Soc. U.K., 86, 335

—, Dwyer, R. St. C., Garland, J. A., Jones, B. R., Treharne, J. D., Dunlop, E. M. C., FreedMan, A., and RACE, J. W. (1967) Amer. F. Ophthal., 63, 1064

JoNEs, B. R. (1960) Rev. int. Trachome, 37, 600

- (1961) Trans. ophthal. Soc. U.K., 81, 367

- (1964a) Brit. F. vener. Dis., 40, 3

(1964b) Rev. int. Trachome, 41, 425

(1965) 'The relation of inclusion conjunctivitis to trachoma and the relation of agents isolated from these and related conditions to isolates of Bedsonia from other human and animal disease'. WHO Scientific Group on Trachoma Research VIR/TRACH/WP/7.65 
- Al-Hussaini, M. K., and Dunlop, E. M. C. (1964) Brit. F. vener. Dis., 40, 19

,,--- (1965) Rev. int. Trachome, 42, 27

- - - - Emarah, M. H. M., Freedman, A., Garland, J. A., HARPER, I. A., RACE, J. W., DUTOIT, M. S., and Treharne, J. D. (1966) Trans ophthal. Soc. U.K., 86, 291

- ANdrews, B. E., Henderson, W. G., and Schofield, P. B. (1957) Ibid., 77, 291

- and Collier, L. H. (1962) Ann N.Y. Acad. Sci., 98, 212

$\longrightarrow$, - and Smith, C. H. (1959) Lancet, 1, 902

SChachter, J. (1967a) Amer. F. Ophthal., 63, 1049

- (1967b) Ibid., 63, 1082

Treharne, J. D. (1971). In 'Trachoma and Allied Diseases, 1970', ed. R. L. Nichols. Excerpta Medica, Amsterdam and New York. I.C.S. No. 223, p. 435

Davey, S. J., Gray, S. J., and Jones, B. R. (1972) Brit. F. vener. Dis., 48, 18

Katzenelson, E., Davey. S. J. and Gray, S. J. (1971) In 'Trachoma and Allied Diseases, 1970', ed. R. L. Nichols. Excerpta Medica, Amsterdam and New York. I.C.S. No. 223, p. 289

Wang, San-pin, and Grayston, J. T. (1970) Amer. $\mathcal{F}$ Ophthal., 70, 367

- - (1971). In 'Trachoma and Allied Diseases, 1970', ed. R. L. Nichols. Excerpta Medica, Amsterdam and New York. I.C.S. No. 223, p. 305
Progrès et projets dans l'étude de certaines maladies dues à l'infection par des Chlamydia du sous-groupe $A$

SOMMAIRE

Jusqu'à ces temps derniers, les progrès de l'étude des maladies génitales dues aux Chlamydia étaient entravés par le manque de méthode microbiologique sensible pour la détection et l'identification.

(1) La mise au point d'un système de culture de cellules de McCoy irradiées, combinant la centrifugation des specimens cliniques et l'emploi d'un support cellulaire à une seule couche, s'est montrée être une méthode de détection plus sensible que celles utilisées auparavant. Ultérieurement, des modifications apportées à la technique des cultures cellulaires ont rendu le dispositif encore plus pratique et plus rapide en tant qu'aide au diagnostic.

(2) L'introduction du test de typage par micro-IF a pallié l'absence de marqueurs biologiques efficaces pour identifier, séparer et établir le rôle des différentes souches dans la détermination du pouvoir pathogène et dans les études épidémiologiques. L’épreuve a facilité le sérotypage des agents du groupe Chlamydia provenant d'infections oculaires, génitales et rectales à Londres, ou de spécimens oculaires isolés à partir de trachome ou dans des zones d'endémie trachomateuse; les agents TRIC ont ainsi été divisés en six séro-types principaux. Les agents de la LGV peuvent maintenant être facilement distingués des agents TRIC et, en outre, peuvent être classés en trois séro-types principaux.

(3) L'application du test de micro-IF pour la titration de l'anticorps spécifique de type dans le sérum des malades semble devoir offrir une méthode indicative de l'infection chlamydiale bien plus sensible que celles utilisées auparavant. 